\title{
Corrigendum: Arabidopsis thaliana as a model for the genetics of local adaptation
}

Brandon Gaut

Nat. Genet. 44, 115-116 (2012); published online 27 January 2012; corrected after print 27 April 2012

In the version of this article initially published, there was a mistake in reference 15 . This reference has been corrected in the HTML and PDF versions of the article.

\section{Erratum: A transposon in tb1 drove maize domestication}

Miltos Tsiantis

Nat. Genet. 43, 1048-1050 (2011); published online 27 October 2011; corrected after print 27 April 2012

In the version of this article initially published, a study by Studer et al. was incorrectly cited as being by Deng et al. The correct sentence should read: "Studer et al. present a clear picture of how maize was domesticated by events operating at different scales: biological and cultural ${ }^{5}$ ". The error has been corrected in the HTML and PDF versions of the article.

\section{Erratum: Common variants at 6q22 and 17q21 are associated with intracranial volume}

\author{
M Arfan Ikram, Myriam Fornage, Albert V Smith, Sudha Seshadri, Reinhold Schmidt, Stéphanie Debette, Henri A Vrooman, \\ Sigurdur Sigurdsson, Stefan Ropele, H Rob Taal, Dennis O Mook-Kanamori, Laura H Coker, W T Longstreth Jr, Wiro J Niessen, \\ Anita L DeStefano, Alexa Beiser, Alex P Zijdenbos, Maksim Struchalin, Clifford R Jack Jr, Fernando Rivadeneira, Andre G Uitterlinden, \\ David S Knopman, Anna-Liisa Hartikainen, Craig E Pennell, Elisabeth Thiering, Eric A P Steegers, Hakon Hakonarson, \\ Joachim Heinrich, Lyle J Palmer, Marjo-Riitta Jarvelin, Mark I McCarthy, Struan F A Grant, Beate St Pourcain, Nicholas J Timpson, \\ George Davey Smith, Ulla Sovio, the Early Growth Genetics (EGG) Consortium, Mike A Nalls, Rhoda Au, Albert Hofman, \\ Haukur Gudnason, Aad van der Lugt, Tamara B Harris, William M Meeks, Meike W Vernooij, Mark A van Buchem, Diane Catellier, \\ Vincent W V Jaddoe, Vilmundur Gudnason, B Gwen Windham, Philip A Wolf, Cornelia M van Duijn, Thomas H Mosley Jr, \\ Helena Schmidt, Lenore J Launer, Monique M B Breteler \& Charles DeCarli for the Cohorts for Heart and Aging Research in Genomic \\ Epidemiology (CHARGE) Consortium \\ Nat. Genet. 44, 539-544 (2012); published online 15 April 2012; corrected online 27 April 2012
}

In the version of this article initially published online, the percentage of females in the AGES study in Table 1 was left blank. This number should be $59 \%$. The error has been corrected for the PDF and HTML versions of this article. 